\title{
Research and Application of Double-Reheat Boiler in China
}

\author{
Hu Liu*, Pengfei Yu, Jingwen Xue, Lei Deng (1) and Defu Che
}

State Key Laboratory of Multiphase Flow in Power Engineering, School of Energy and Power Engineering, Xi'an Jiaotong University, Xi'an 710049, China; yupf95@stu.xjtu.edu.cn (P.Y.); jingwenxue@stu.xjtu.edu.cn (J.X.); leideng@mail.xjtu.edu.cn (L.D.); dfche@mail.xjtu.edu.cn (D.C.)

* Correspondence: epeliuhu@mail.xjtu.edu.cn

check for

updates

Citation: Liu, H.; Yu, P.; Xue, J.;

Deng, L.; Che, D. Research and

Application of Double-Reheat Boiler

in China. Processes 2021, 9, 2197.

https://doi.org/10.3390/pr9122197

Academic Editors: Zhiqiang Sun,

Yi Man and Sheng Yang

Received: 4 November 2021

Accepted: 29 November 2021

Published: 6 December 2021

Publisher's Note: MDPI stays neutral with regard to jurisdictional claims in published maps and institutional affiliations.

Copyright: (C) 2021 by the authors. Licensee MDPI, Basel, Switzerland. This article is an open access article distributed under the terms and conditions of the Creative Commons Attribution (CC BY) license (https:// creativecommons.org/licenses/by/ $4.0 /)$.

\begin{abstract}
The ultra-supercritical (USC) double-reheat technology is an immediate area of research focus in China, since the thermal efficiency of USC double-reheat unit is higher than the USC singlereheat unit. The parameters and capacity of USC double-reheat unit in China have made major breakthroughs, and the thermal efficiency of the units are as high as $47-48 \%$, which is the highest in the world. USC double-reheat boiler is one of the most important devices for USC double-reheat unit, and the design concept and precision have a vital effect on the operation of boiler and power station. The most difficult and important factors in the design of double-reheat boiler are the layout of heating surface and the steam temperature regulation method. Therefore, this work summarizes the arrangement of heating surface and temperature regulation method of existing double-reheat boiler in China. It is hoped that the work will set a benchmark for the development of double-reheat boiler and the future $700{ }^{\circ} \mathrm{C}$ power generation unit in the world.
\end{abstract}

Keywords: ultra-supercritical double-reheat boiler; heating surface layout; steam regulation method

\section{Introduction}

Coal is the primary energy source and plays a dominant role in thermal power generation in China. Pulverized coal fired power plants consume $50 \%$ of the coal in China and contribute nearly $50 \%, 35 \%$, and $35 \%$ of the total SOx, NOx, and dust emissions, respectively [1]. The emissions of $\mathrm{CO}_{2}$, which is a greenhouse gas, are another serious environmental problem caused by coal combustion. These pollution problems are harmful to both human health and the development of society [2,3].

It is generally understood that the improvement in thermal efficiency is bound with low coal consumption and low pollution emissions as well as low $\mathrm{CO}_{2}$ emissions $[4,5]$. Especially, $\mathrm{CO}_{2}$ emissions decrease almost linearly with the increase of net plant efficiency [6], which confirms the feasibility of reducing $\mathrm{CO}_{2}$ emissions by improving the net plant efficiency [4,7]. Based on the above cognition, the development of high-parameter and large-capacity ultra-supercritical (USC) units with high efficiency for reducing pollutant emissions is greatly promoted in the world.

Since the 1990s, different countries have conducted high-temperature, high-pressure, and large-capacity USC coal-fired units. The parameters of the units are developed from subcritical, supercritical, and ultra-supercritical characteristics and have improved the power generation efficiency from $35 \%$ to $43 \%$ [4]. Especially, the USC units of $35 \mathrm{MPa} / 700{ }^{\circ} \mathrm{C}$ with thermal efficiency exceeding $50 \%$ are currently considered to be the most advanced and efficient power generation facilities. As one of the $35 \mathrm{MPa} / 700{ }^{\circ} \mathrm{C}$ USC units, AD700 cycle has been operated since 1998 in Europe [8]. Besides, the United States, Japan, and China have also planned to develop $700{ }^{\circ} \mathrm{C}$ USC power generation technology. However, the promotion of this unit needs to overcome the difficulties in terms of strength of metal material at $35 \mathrm{MPa} / 700{ }^{\circ} \mathrm{C}$, resistance of corrosion at high temperature, and the service life of the metal material [8]. Actually, the $700{ }^{\circ} \mathrm{C}$ metal material is too expensive to be used on a large scale, which greatly limits the development of USC units. Until now, there is no such unit operating in the world [9]. 
The USC double-reheat unit is a result of USC units proposed between the USC singlereheat unit and the future $35 \mathrm{MPa} / 700{ }^{\circ} \mathrm{C}$ unit. Furthermore, the double-reheat unit can improve the average heat absorption temperature of the Rankine cycle [10]. In addition, it can reduce the exhaust humidity in low pressure cylinder, which is beneficial for the safe operation of steam turbine. Compared with the USC single-reheat unit, the USC doublereheat unit has improved thermal efficiency (by 1.0\%) [6]. Generally, the thermal efficiency of double-reheat unit with the parameters of $30.0 \mathrm{MPa} / 600 / 620 / 620^{\circ} \mathrm{C}$ is about $2 \%$ higher than the traditional single-reheat unit having the parameters of $24.1 \mathrm{MPa} / 566 / 566{ }^{\circ} \mathrm{C}$. Moreover, there is no significant technical bottleneck, and the existing materials can meet the requirements of USC double-reheat unit production with the parameters of $30.0 \mathrm{MPa} / 600 / 620 / 620^{\circ} \mathrm{C}$. Therefore, China has identified the USC double-reheat unit as the key point of future research for the high-parameter power generation unit, because the energy efficiency and environmental protection become more and more important with the development of economy. Therefore, a great number of studies have been conducted on clean and efficient coal combustion and power generation, in which the double-reheat technology was the main focus.

The double-reheat boiler is one of the most important devices in double-reheat units, and it consists of technological integration of steam temperature regulation, combustion organization, heating surface arrangement, and pollution control of USC single-reheat boiler. However, it is more complicated than the single-reheat boiler [11]. Firstly, it is difficult to design and arrange the heating surface in furnace since there are two stages of reheat heating surfaces in the double-reheat boiler. Secondary, the mass flow rate of the main steam of double-reheat boiler decreased compared to that of the singe-reheat boiler. Thirdly, the water-vapor flow circuitry is complicated and the dynamic response characteristics of boiler change significantly. Therefore, the temperature regulation methods of main steam and reheat steam changes. Finally, the steam pressure and tube metal temperature nearly reach the material limitation. The metal temperature of the heating surface should be precisely controlled.

Admittedly, the combustion system and pollution control system of the double-reheat boiler are similar to the single-reheat boiler. However, the layout of boiler heating surface and the steam temperature regulation method are different from the single-reheat boiler. These are fundamental to boiler design and can ensure the boiler operates safely at the rated condition. This work summarizes the arrangement of heating surface first, and then presents the steam temperature regulation method of the double-reheat boiler in China. The objective of this work is to provide reference for the development and design of a high-parameter, large-capacity double-reheat boiler and the $35 \mathrm{MPa} / 700{ }^{\circ} \mathrm{C}$ boiler in the near future, but the combustion problems [12-14] and flexibility [15-17] will not be involved.

\section{Brief History of Double-Reheat Boiler}

The double-reheat boiler has been investigated in the United States, Europe, and Japan from the 1970s to the 1990s, and the parameters of most boilers are around $560{ }^{\circ} \mathrm{C}$ and $24 \mathrm{MPa}[18,19]$. The companies in these countries have carried out research on doublereheat technology and have obtained a variety of experimental and practical operational data. As a typical representative, among the operating double-reheat units in the world in 1998, the Nordjyilands Vaerker power plant in Denmark operating with a $400 \mathrm{MW}$ and $29.0 \mathrm{MPa} / 580 / 580 / 580{ }^{\circ} \mathrm{C}$ double-reheat boiler had the highest thermal efficiency of $47 \%[18,19]$.

However, in the last two decades, no new double-reheat unit was built due to low electricity demand and adjustment of energy structure in these countries. In contrast, the USC double-reheat unit has attracted a lot of attention in China in recent years [20].

In China's 10th Five-Year Plan, the USC double-reheat power generation technology was identified as a focus project [21]. During the 12th Five-Year period [22], three power plants were approved by National Energy Administration to construct USC double-reheat 
units. Additionally, it is also the key technology for the "action plan for retrofitting and upgrading of energy conservation and emission reduction for thermal power plants (20142020)" [23]. Based on these plans, universities, electric power design institutes, and the major power device manufacturers in China have carried out a lot of research on the double-reheat boiler and have made remarkable progress.

Many power generation projects involving double-reheat technology have been approved in China. Especially, the three power plants approved in the 12th Five-Year Plan have already been finished and their commercial application shows the development prospects of this technology in China. The double-reheat boilers in China are equipped with the capacities of $1000 \mathrm{MW}$ and $660 \mathrm{MW}$, with steam pressure over $30 \mathrm{MPa}$ and temperatures over $600{ }^{\circ} \mathrm{C}$. The design efficiency for power generation is as high as $47-48 \%$ [24], which is the highest level worldwide. The design and operational experience of double-reheat units with high parameters and high capacity in China will provide a useful reference for the development of this technology.

\section{Scheme for Heating Surface Arrangement}

Considering the different absorption characteristics of superheated steam and two stages reheated steam, the superheat and reheat exchanger systems are well designed and arranged to ensure that the heat absorption ratio of each section of the heating surface is reasonably distributed. Until now, there have been three types of double-reheat boilers in China, and they are the inverse U-type, tower-type, and T-type double-reheat boilers.

\subsection{Inverse U-Type Double-Reheat Boiler}

Presently, there are two kinds of inverse U-type double-reheat boilers operating in China. One is triple back passes and the other is double back passes.

\subsubsection{Inverse U-Type with Triple Back Passes}

The inverse U-type double-reheat boiler with triple back passes adopts a wall-fired combustion system, single furnace with spiral-wound and vertical pipe combined watercooled wall, and three parallel vertical back passes split by the baffle wall in the back pass [25]. The sketch of this boiler is shown in Figure 1, and it operates at $32.6 \mathrm{MPa} / 605 / 623$ / $623^{\circ} \mathrm{C}$. As can be seen, the superheater and the first-stage reheater are divided into three sections, and the second-stage reheater is divided into two sections. In this work, the heating surface which is divided into three sections are respectively named as primary, middle, and final, and the heating surface which is divided into two sections are respectively named as primary and final.

Obviously, the most significant feature of the boiler is the triple back passes. In addition, the superheater adopts a convective \& radiant \& semi-radiant heat exchanger system. This means the primary superheater absorbs energy by convection, the middle superheater absorbs energy from high temperature flue gas by radiation, and the final superheater absorbs energy primarily by convection and secondarily by radiation. While the first-stage reheater uses the convective \& semi-radiant \& convective heat exchanger system. Additionally, the second-stage reheater employs a convective \& convective heat exchanger system. It is inappropriate to dispose the reheater in the high flue gas temperature zone because the steam pressure in the two stage reheaters both are lower than that in the superheater, which means a lower steam density and lower heat transfer coefficient. Moreover, the second-stage reheater was disposed as convective heat exchangers only in the lower flue gas temperature zone, since the steam pressure in the second-stage reheater is lower than that in the first-stage reheater. 


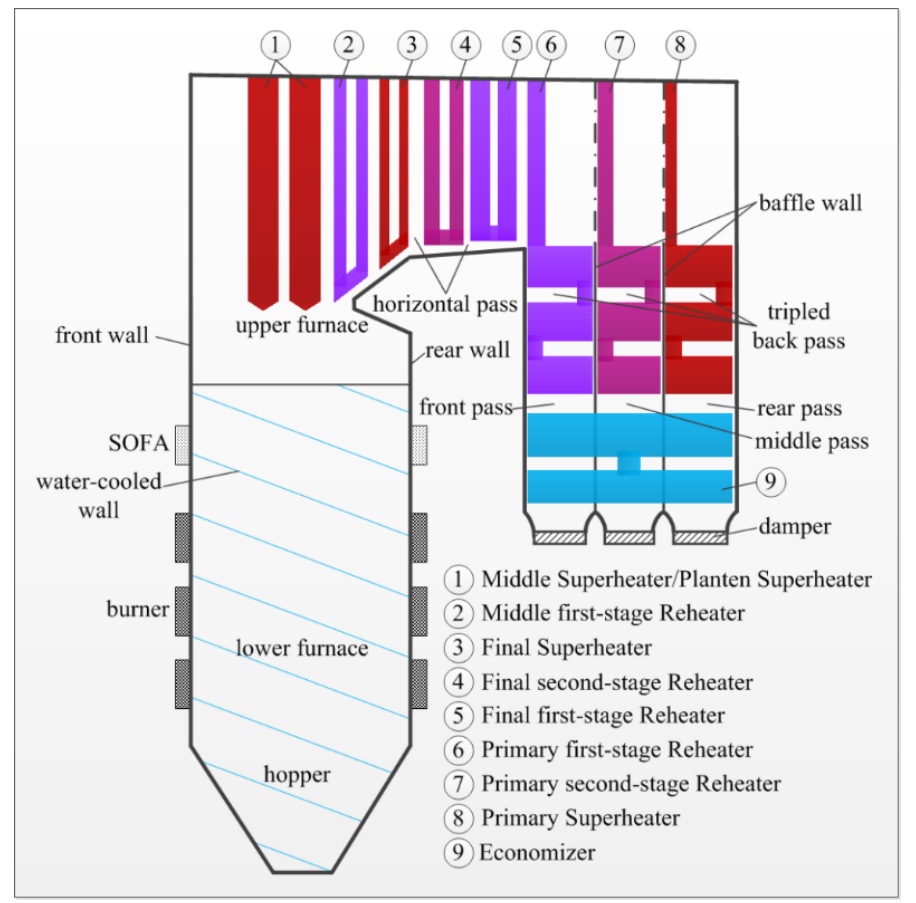

Figure 1. Wall-fired double-reheat inverse U-type boiler with triple back passes.

\subsubsection{Inverse U-Type with Double Back Passes}

The U-type double back passes boiler consists of a single furnace, a wall-fired combustion system, with spiral-wound water-cooled wall in the lower furnace and vertical water-cooled wall in the upper furnace. The schematic of the boiler is shown in Figure 2 [25], and it operates at $32.6 \mathrm{MPa} / 605 / 623 / 623^{\circ} \mathrm{C}$. The back pass is split into two parallel vertical back passes using the baffle wall, which are respectively known as the main pass and by-pass.

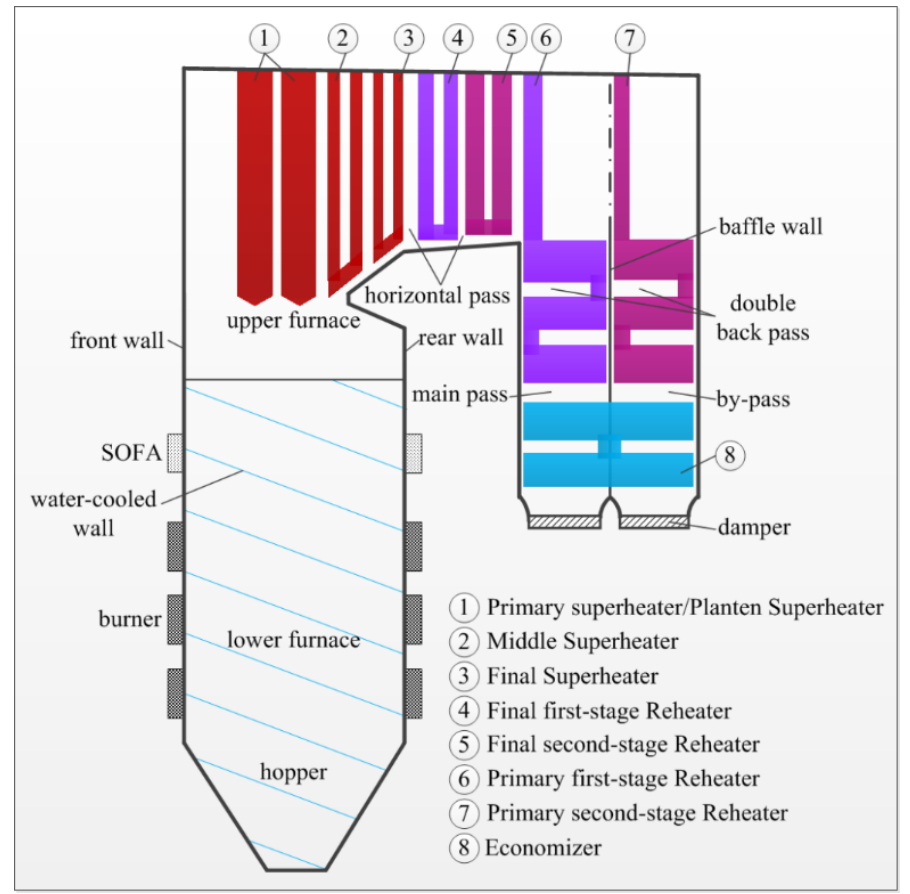

Figure 2. Wall-fired double-reheat inverse U-type boiler with double back passes.

The superheater is divided into three sections, while both the first-stage reheater and second-stage reheater are divided into two sections. The superheater adopts the radiant 
\& semi-radiant \& semi-radiant exchanger system, while the two stage reheaters are pure convective heating surfaces. Therefore, the steam temperature of the two stage reheaters is sensitive to the flow rate of flue gas, and the distribution of heat absorption between the superheated steam and reheated steam can be adjusted using flue gas recirculation (FGR).

The characteristics of this scheme are as follows. Firstly, the final first-stage reheater and final second-stage reheater are arranged in the horizontal pass to ensure the safety of the reheater, where the flue gas temperature is relatively low. Secondly, the steam temperature is sensitive to FGR since both of the two stage reheaters are arranged as convective heat exchangers.

Figure 3 shows another inverse U-type double-reheat boiler with doubled back passes, and the rated parameters are the same as the boiler shown in Figure 2. Compared with the boiler shown in Figure 2, this boiler adopts the tangentially-fired combustion system and vertical membrane water-cooled wall. Furthermore, the superheater adopts radiant \& radiant \& semi-radiant heat exchanger system [26]. Both of the two stage reheaters employ the convective \& convective heat exchanger system, which is the same as the doubled back passes boiler introduced earlier. Therefore, the steam temperatures of the two stage reheaters are also sensitive to FGR.

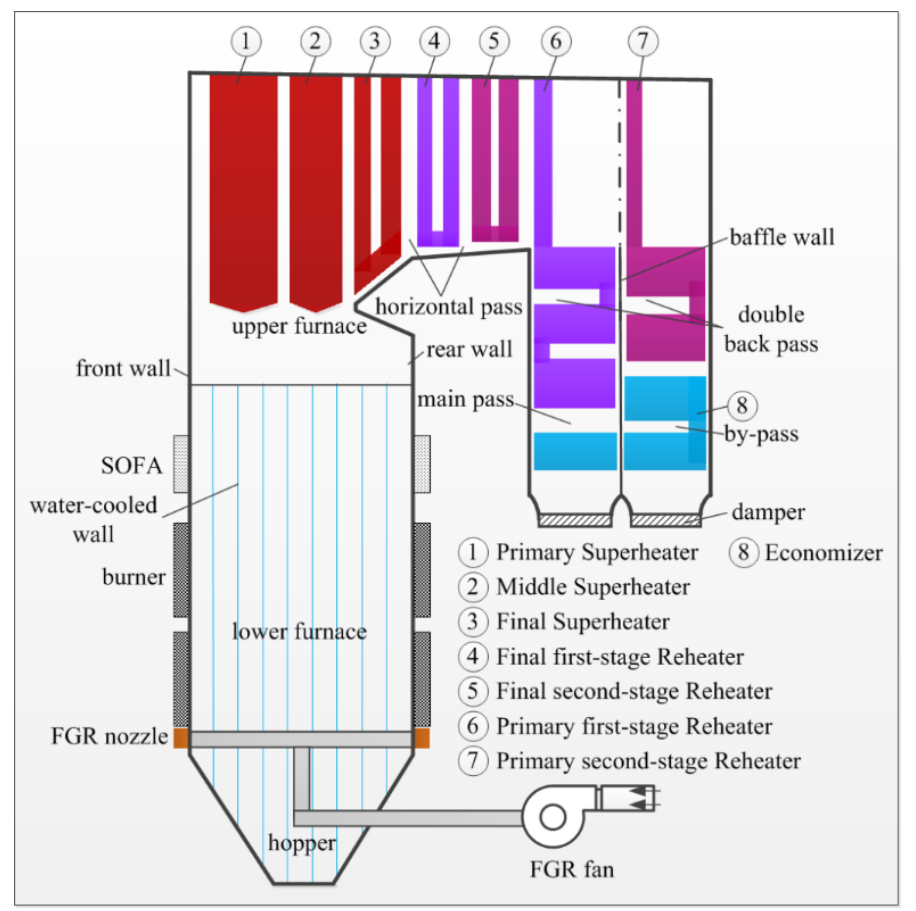

Figure 3. Tangentially-fired double-reheat inverse U-type boiler with double back passes.

In short, for the inverse U-type double-reheat boiler, in order to ensure the heat absorption and safe operation of superheaters, a primary or middle superheater should be arranged in the upper furnace with high flue gas temperature. The reason is that the temperature of the working fluid and tube metal of primary and middle superheaters is relatively low. The final superheater should be arranged in the zone with middle flue gas temperature to prevent the overheating of the final superheater tube. The final sections of the first-stage reheater and second-stage reheater are also arranged in the middle flue gas temperature zone to prevent the overheating of reheater tube. Furthermore, the primary sections of the first-stage reheater and second-stage reheater are generally arranged in the back passes of the boiler.

\subsection{Tower-Type Double-Reheat Boiler}

Different from the two kinds of inverse U-type double-reheat boilers, the towertype layout with tangentially-fired double-reheat boiler is also widely adopted in China. 
Generally, the superheater, reheater, and economizer heat exchanger systems of the towertype boiler are all horizontally arranged in the upper furnace. The flue gas flows over them and then turns downward to the outlet of the boiler. Therefore, the tower-type boiler is obviously higher than the inverse U-type boiler, and the layout characteristics of heating surfaces are different from the inverse U-type boiler.

Considering the characteristics of the double-reheat boiler, the superheater and two stage reheaters of tower-type double-reheat boiler are all divided into two sections, as shown in Figure $4[27,28]$, and they operate at $32.6 \mathrm{MPa} / 605 / 623 / 623^{\circ} \mathrm{C}$. In addition, the final first-stage reheater and final second-stage reheater are divided into two parts, namely the low-temperature part and high-temperature part, respectively. The final superheater is arranged between the two parts of the two reheaters. This layout is called the combined heating surface, and this layout was adopted in some $1000 \mathrm{MW}$ and $660 \mathrm{MW}$ doublereheat boilers.

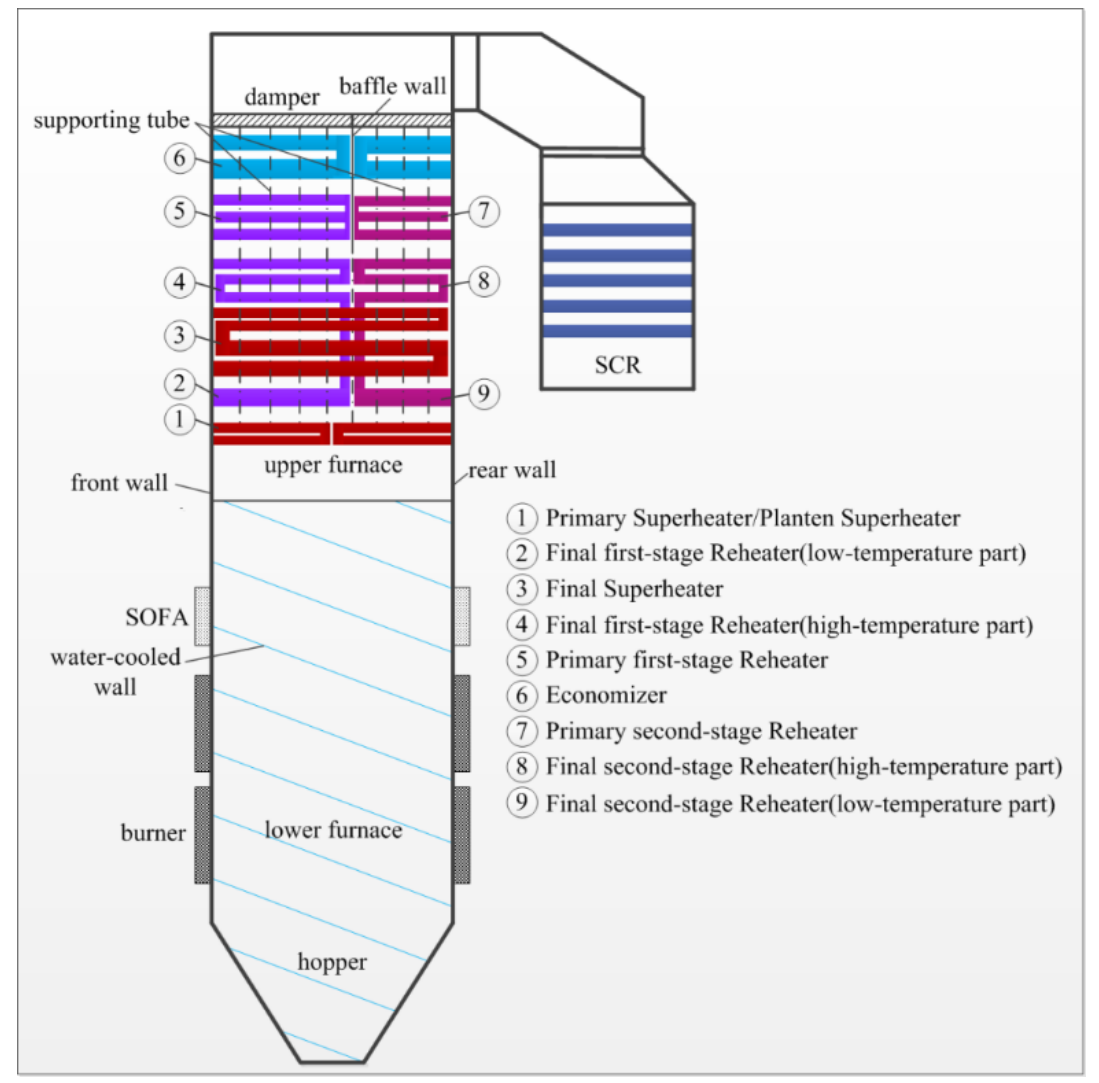

Figure 4. Schematic of the double-reheat tower-type boiler with combined heating surface.

As can be seen from Figure 4, the main feature of the heating surface layout of this boiler is that the final superheater and final section of the two reheaters are combined together. Specifically, the low-temperature part of the two reheaters is arranged near the combustion zone between the platen superheater and final superheater, and the high-temperature parts of the two reheaters are arranged in the downstream of the final superheater. Obviously, the low-temperature parts of final first-stage reheater and final second-stage reheater are designed as radiative absorption heating surface and arranged near the high temperature zone; this arrangement improves the radiation absorption ability and ensures the heating surfaces are sensitive to the position of fireball in the furnace. Meanwhile, the corresponding high-temperature parts of the two reheaters are designed as convective absorption heating surfaces and arranged at the middle temperature zone. With this scheme, the heating surface is much safer, more economical, and reliable, although the outlet steam temperatures of the final first-stage reheater and final second-stage reheater are high. 
Figure 5 shows another heating surface layout of tower-type double-reheat boiler [29,30], and it also operates at $32.6 \mathrm{MPa} / 605 / 623 / 623{ }^{\circ} \mathrm{C}$. As can be seen, the superheater is divided into three sections, and both the two stage reheaters are arranged as two sections. Both the primary and final superheaters are disposed in the upper furnace upstream the furnace exit, while the final first-stage reheater, final second-stage reheater, and the middle superheater are subsequently disposed downstream the furnace exit. Then, the flue gas is divided into two ways to meet the primary first-stage reheater and primary second-stage reheater and the economizer. Obviously, the arrangements of the heating surfaces are different from the layout characteristics of tower-type double-reheat boiler reported earlier. However, it was found that when the later tower-type double-boiler was put into commercial operation, especially under low load, the superheater of the boiler was over-heated, and the temperatures of steams in the two stage reheaters made it difficult to reach the rated value [30]. The reason for this may be that the primary and final superheater both are arranged just downstream of the furnace exit, and lots of heat was absorbed by the two heating surfaces.

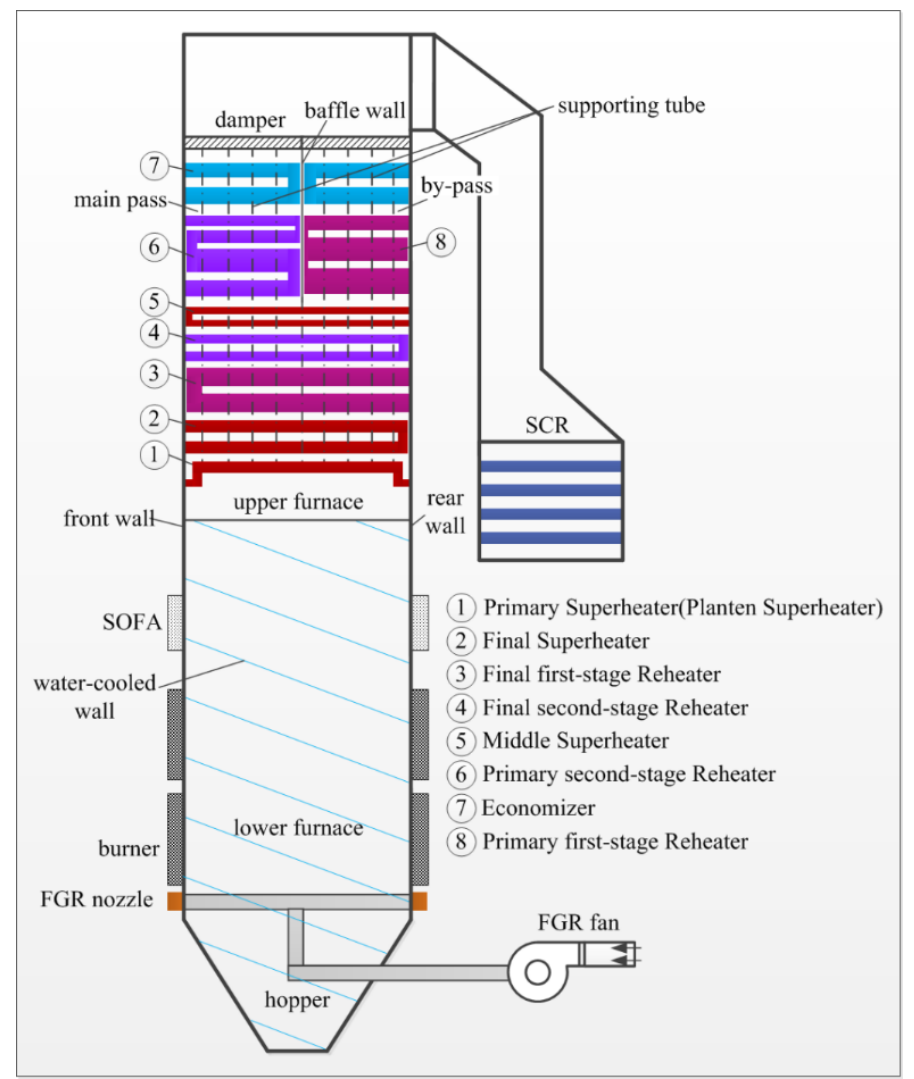

Figure 5. Schematic of the double-reheat tower-type boiler without combined heating surface.

In order to solve this problem, a new concept of combined heating surface layout design was proposed, which is similar to the arrangement of the former tower-type doublereheat boiler. However, its heating surface arrangement is comparatively far away from that of the former. The detailed combined heating surface of the new boiler is shown in Figure 6. It is obvious that the final first-stage reheater is divided into two parts, namely the low-temperature part and high-temperature part. Additionally, the second-stage reheater is arranged between the low-temperature part and high-temperature part of the final firststage reheater. The specific effect will be obtained once the unit is commercially operated. 


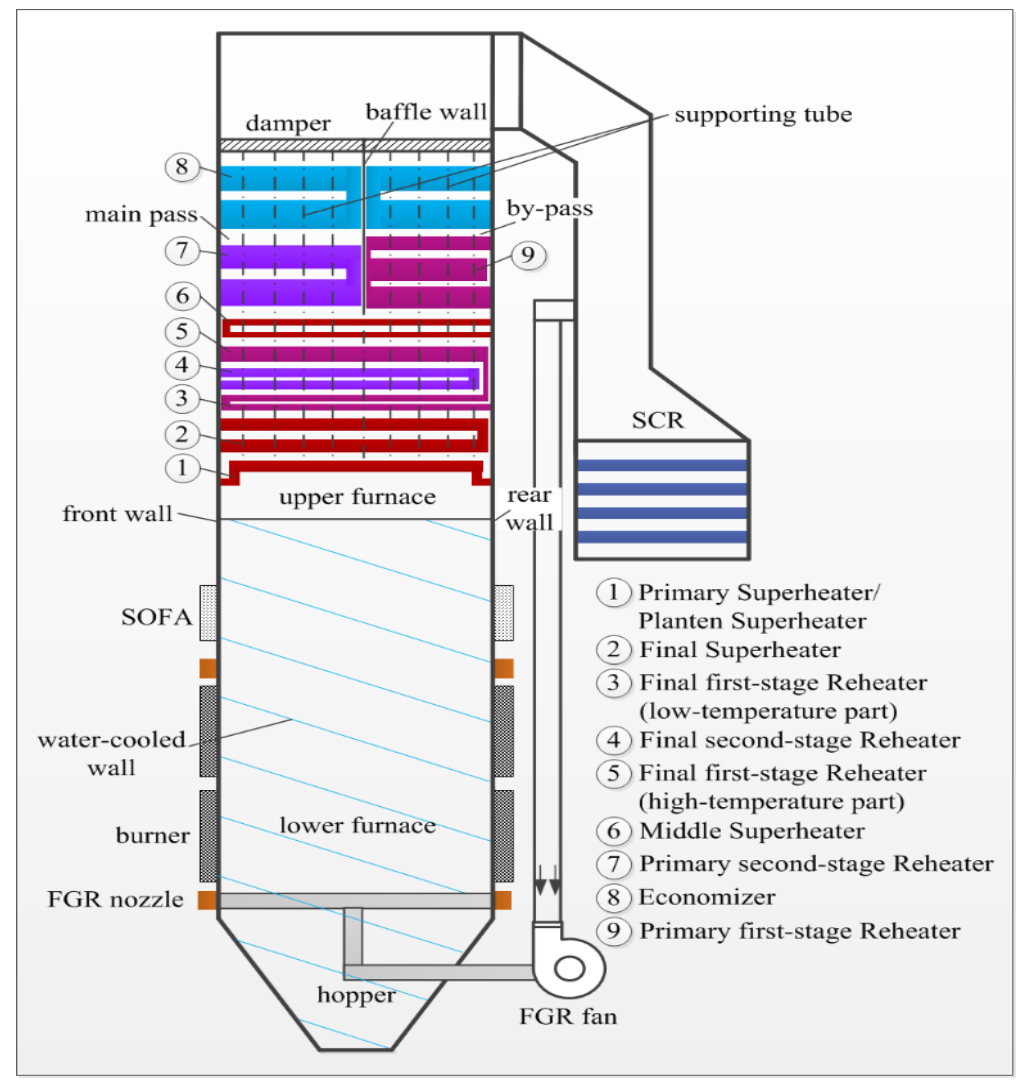

Figure 6. Another schematic of the double-reheat tower-type boiler with combined heating surface.

\subsection{T-Type Boiler}

The T-type layout was also adopted in the double-reheat boiler. Figure 7 shows the layout details of the heating surface, which is significantly different from the inverse U-type boiler and tower-type boiler [25]. The T-type boiler is a single furnace and double-chamber wall-tangentially-fired boiler, with the spiral-wound water-cooled wall in the lower furnace and vertical tube water-cooled wall in the upper furnace. The back pass is divided into two portions arranged symmetrically on both sides of the furnace. The superheater, first-stage reheater, and second-stage reheater are all divided into three sections, which are disposed symmetrically on the left and right sides of the boiler. The primary superheater and middle superheater are arranged symmetrically on the upper furnace, while the primary first-stage reheater, primary second-stage reheater, middle first-stage reheater, and middle second-stage reheater are arranged symmetrically. However, the final first-stage reheater and final second-stage reheater are in a cross arrangement. Figure 7 indicates that the superheater adopts a radiant \& radiant \& convective exchanger system, and both the two stage reheaters adopt the convective \& semi-radiant \& convective exchanger system. With this arrangement, the heat absorption of the superheater and the resistance of flue gases can be balanced on both the sides. In addition, as the back passes are arranged symmetrically on both sides of the furnace, the height of the furnace exit window can be reduced. The flue gas flow in the horizontal pass can be improved and the thermal maldistribution of the flue gas across the window height can be mitigated. 


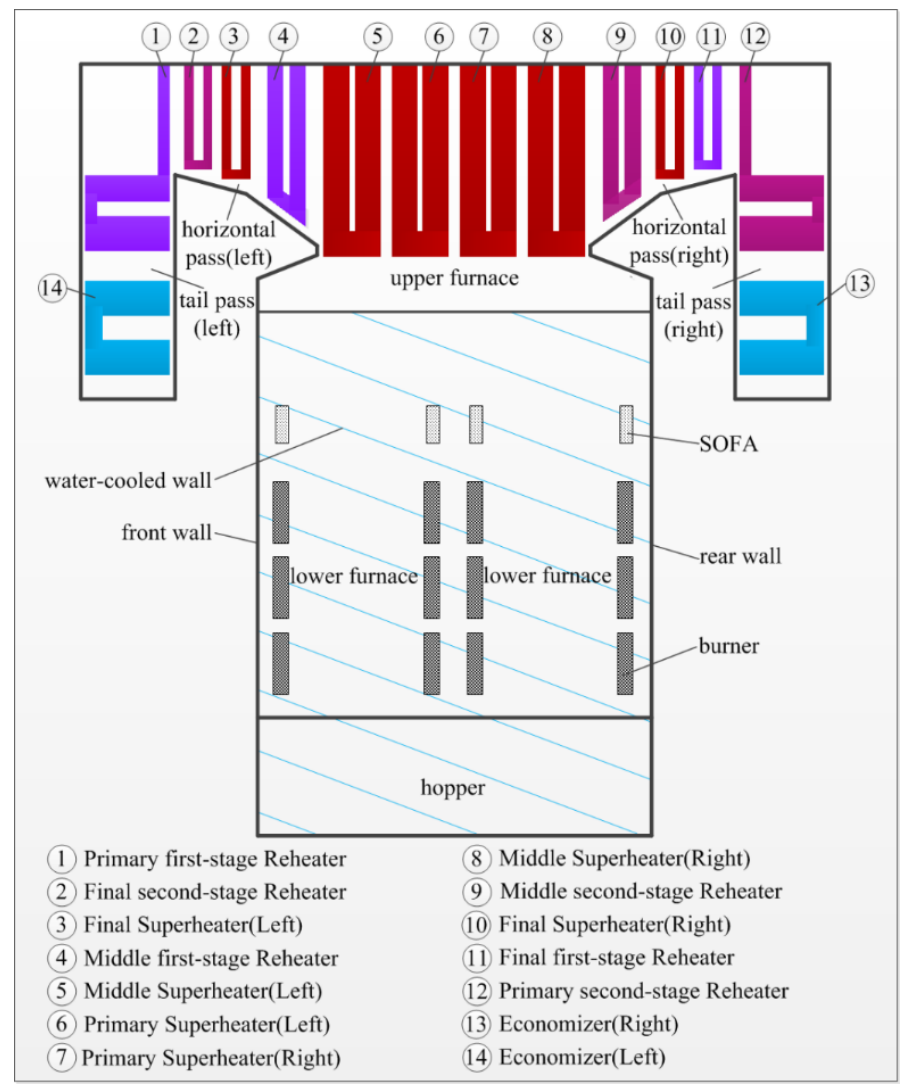

Figure 7. Schematic of the T-type double-reheat boiler.

\section{Methods for Regulating Steam Temperature}

There is a close relationship between the arrangement of heating surface and the method for regulating the steam temperature. The purpose of various methods for regulating the steam temperature is to guarantee the main steam temperature and the two stage reheat steam temperature meet the rated value for double-reheat boilers.

For the once-through boiler, the water/coal ratio is used as the principal method to adjust the main steam temperature, while the spray attemperators are used as the auxiliary system. Meanwhile, the principal methods for regulating the steam temperature of the reheater include tilting burners (TB), flue gas damper (FGD), flue gas recirculation (FGR), and spray attemperation (SA). The former three are the major methods and are usually combined to control the steam temperature of the reheater. Although SA is adopted in all types of double-reheat boilers in the reheat system, it can only be initiated under accident, startup, suspension condition, and variable load stage. This is because SA affects the efficiency of the unit.

\subsection{Methods for Regulating the Superheater}

The key method used to regulate the main steam temperature is maintaining the water/coal ratio, which is defined as the ratio of feed water to coal. An improper water/coal ratio will obviously affect the main steam temperature. If the water/coal ratio fluctuates by $10 \%$, the main steam temperature will change by about $100{ }^{\circ} \mathrm{C}$ [31]. Therefore, the control of water/coal ratio directly affects the safety and stability of boiler, and it is necessary to maintain the water/coal ratio to a constant value to regulate the main steam temperature. All types of double-reheat boilers mentioned above used water/coal ratio to control the main steam temperature.

In addition, there are two stages of SA arranged at the intermediate point between the two sections of the superheater to prevent the overheating of the main steam and decrease the deviation of the two sides, as shown in Figure 8. 


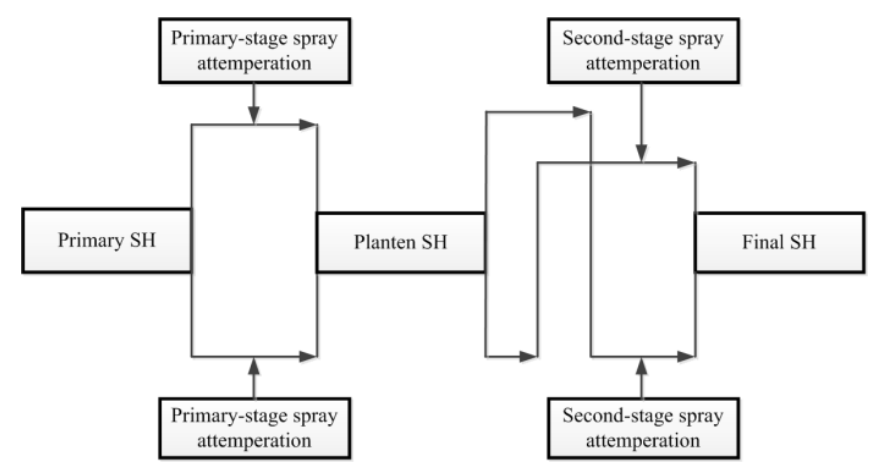

Figure 8. Arrangement of the two stage spray attemperation.

At present, there are two methods to control the water/coal ratio of double-reheat boiler in China. One is the coal following feed water and the other is the feed water following coal. For the once-through boiler, feed water following coal means the water/coal ratio is controlled by the flow rate of feed water, while coal following feed water means the water/coal ratio is controlled by the flow rate of coal. The roles of the two methods in controlling water/coal ratio are quite different [32]. The water/coal ratio is more sensitive to the flow rate of feed water than to coal, which means that the ratio can be adjusted quickly by changing the flow rate of feed water. The advantage of feed water following coal is that the outlet temperature of steam separator can be accurately controlled, thus making a preferential choice for the main steam temperature and the metal temperature of tubes. However, this strategy shows limited control over the main steam pressure. Although coal following feed water provides stable pressure of the main steam, it is difficult to control the outlet temperature of steam separator, main steam temperature, and tube metal temperature, especially for the double-reheat boiler with a direct pulverizing system [32-34].

Additionally, there are more heating surfaces in the double-reheat boiler than those in the single-reheat boiler, and the arrangements of superheater and reheater in the doublereheat boiler are more complicated. Therefore, it is more difficult to control the main steam pressure and temperature. In addition, most of the double-reheat boilers are equipped with an FGR system, and the flow rate of FGR affects the heat absorbed in the water-cooled wall, superheater, reheater, and economizer. Because of this, the outlet temperature of the separator is also affected. Therefore, it is difficult to accurately control the steam temperature by adopting the individual methods of feed water following coal or coal following feed water.

Zhao [32] reported that it is appropriate to adopt the water/coal composite control method to maintain the water/coal ratio for the double-reheat boiler, which means that coal following water mainly works in a dynamic process, while the water following coal works in a steady process. Therefore, the outlet temperature of the separator can be adjusted based upon the water/coal composite control method under a certain load. The composite control method can satisfy the requirements of steam temperature regulation in double-reheat boiler.

\subsection{Methods for Regulating the Reheater}

The regulation of the steam temperature of the reheater in the double-reheat boiler is the key point in the design of the double-reheat boiler. Generally speaking, FGD, FGR, and TB are combined to control the steam temperature of the reheater with one of the three methods as the primary method. Although $\mathrm{Xu}$ et al. [35] studied the influence of FGD, FGR, and TB regulation and the result showed that the variation of dampers opening has the greatest influence on the reheat steam temperatures, the regulation method adopted for different boilers depends on the characteristics of the heating surface arrangement, combustion system, operational mode, initial investment, and the efficiency of the power plant. 


\subsubsection{Inverse U-Type Double-Reheat Boiler}

\section{- Inverse U-type with triple back passes}

The triple back passes is designed to adapt to the requirements of the steam temperature control method of FGD in inverse-U type double-reheat boiler. As illustrated in Figure 1, primary first-stage reheater, primary second-stage reheater, and primary superheater are located at the front, middle, and rear passes, respectively. FGD permits proportioning of the flue gas over heat transfer surfaces to regulate the reheat and superheat temperatures, and it is arranged at the outlet of the three gas passes. In the double-reheat boiler with triple back pass, the heating surfaces area of primary first-stage reheater and primary second-stage reheater relatively increased to improve the performance of the FGD.

FGD is widely used in steam temperature regulation due to its simple structure, large adjustment range, and limited effect on combustion. However, FGD cannot regulate steam temperature in a transient process, and the damper opening varies nonlinearly with the change in steam temperature. In addition, He [25] reported that most dampers are only effective in the opening range of $0-40 \%$. Furthermore, the dampers are easy to wear out or deposition when the opening is large or small.

FGR is adopted as an alternative temperature regulation method under low load in this type of boiler. However, the recirculation fan is not necessarily needed in the boiler since the recirculated flue gas can be injected into the furnace by the margin of induced draft fan. This system can help in the avoidance of wearing-out problems caused by the adoption of recirculation fan. Because of this, the cost of the operation and maintenance is reduced. In short, the double-reheat boiler having triple back pass adopts FGD + FGR + SA as the steam temperature regulation system, which is relatively simple and requires little initial investment. Additionally, the temperature of the reheat steam will be controlled by spray attemperators only when the boiler is under emergency condition.

- Inverse U-type with double back passes

It can be seen from Figures 2 and 3 that both the double-reheat boilers with double back passes adopt a purely convective heating surface for two stage reheaters. Because of this, FGR is used as the major method to control steam temperature of the two boilers. Moreover, as shown in Figure 9, the extraction and injection positions of FGR are set after the economizer and at the bottom of the furnace, respectively. FGD is adopted to control the steam temperatures between the two stage reheaters in the two boilers. Furthermore, SA will be put into operation when the system is running under accidental conditions.

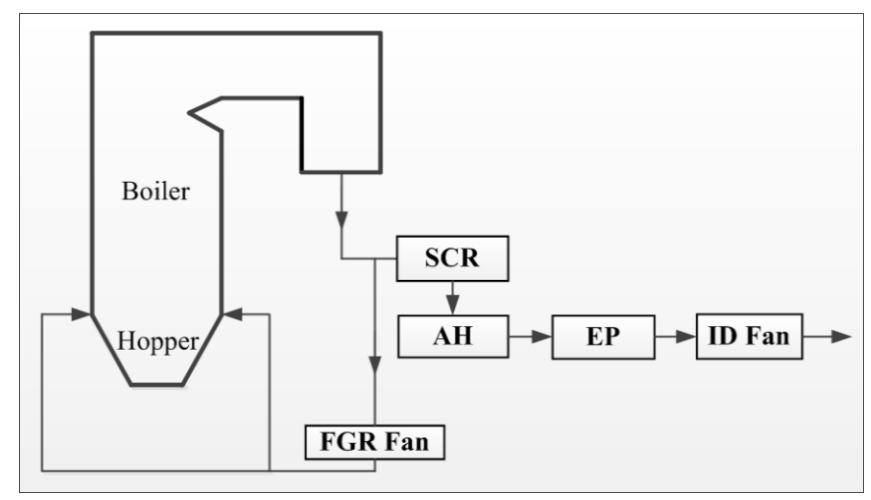

Figure 9. Extract points in the system of double-reheat boiler.

FGR increases the amount of flue gas in furnace and enhances the absorption of convection, which finally realizes the adjustment of heat absorption of main steam and reheat steam. Although FGR is usually adopted to control the steam temperature of boilers fed with natural gas, it can also be useful when adopted for double-reheat boiler fed with coal. However, the working conditions of the recirculation fan are severe due to high temperature of recirculating flue gas combined with serious wearing out by fly ash in the 
boiler fed with coal. In addition, it is necessary to set a certain value of recirculation flue gas in the high load range because the FGR ratio should be decreased to prevent overheating under this condition. Otherwise, SA will need to be operated, and the economic advantage of double-reheat boiler will be affected.

As can be seen in Figure 9, the recirculation flue gas is introduced into the furnace from the nozzle near the hopper, which means the average temperature and heat absorption of furnace will significantly decrease. However, the furnace exit gas temperature changed slightly and the heat absorption of the convection heating surface increased [36]. With the increase in the flow rate of recirculating flue gas, the convective heat absorption and the steam temperature increase.

Tilting burner is also adopted as an auxiliary method in the boiler of tangentially-fired boiler to alter the heat absorption of radiant heating surface, and the variation in primary air nozzle and secondary air nozzle can be $\pm 20^{\circ}$ and $\pm 30^{\circ}$, respectively.

Above all, the steam temperature control method for reheaters of the wall-fired doublereheat boiler is FGR + FGD + SA, while for the tangentially-fired double-reheat boiler, the corresponding method is FGR + FGD + TB + SA.

\subsubsection{Tower-Type Double-Reheat Boiler}

Although both the tower-type double-reheat boilers adopt tangentially-fired combustion system and TB as the steam temperature regulating method for the reheater, the main steam temperature control methods for them are different.

The boiler showed in Figure 8 adopts TB as the main method to control the steam temperature of reheater since both the low-temperature parts of final first-stage reheater and final second-stage reheater are arranged as the radiant heating surface. Therefore, the steam temperature of the reheater is highly sensitive to the position of fireball within the furnace, which can be altered by TB. The burner tilt usually varies within $\pm 20-30^{\circ}$, and the corresponding furnace exit gas temperature can fluctuate by about $110-140^{\circ} \mathrm{C}$. Because of this, the fluctuation in steam temperature can lie within the range of $40-60^{\circ} \mathrm{C}$ [36]. When the boiler operates under low load, the burner tilts positive (upward) to reduce the heat absorption of furnace, and the temperature of the furnace exit increases, and thus the heat absorption of radiant and semi-radiant heating surface increases.

It is worth mentioning that the range of temperature adjustment of TB should be limited to prevent slagging of fuel with low ash fusion point. For TB, in order to avoid the immobility of burner and the erosive wear, it is necessary to strengthen the routine maintenance since the burners do not generally operate at horizontal tilt.

Meanwhile, the balance of steam temperature of two stage reheaters can be controlled by adjusting the position of FGD to change the fraction of flue gas flowing through the primary first-stage reheater and primary second-stage reheater. In addition, there are SA arranged on the reheater pipes to prevent the over-heating of reheat steam and decrease the deviation in the two sides. Above all, the synchronous adjustment of steam temperature of the two stage reheaters depends on TB, whereas the balance adjustment of steam temperature of the two stage reheaters depends on FGD.

This steam temperature control system is obviously simple and can be constructed with little investment. Additionally, with the burner tilt variation of $\pm 20^{\circ}$ and $\pm 30^{\circ}$ for primary air nozzle and secondary air nozzle, the steam temperature of superheater, firststage reheater, and second-stage reheater can reach the rated value within the BMCR load range of $30-100 \%, 50-100 \%$, and $65-100 \%$, respectively. Actually, it is hard to meet the requirement of steam temperature of reheater if only TB is used [37,38]. Therefore, FGR is combined with TB to control the steam temperature of reheater in the new design of the boiler shown in Figure 4, which means that TB is the major steam temperature regulating method for the reheater and FGR is adopted as an auxiliary system. The steam temperature is adjusted by TB only under high load condition, while the FGR system only operates with the minimum flow to prevent the backflow of high temperature flue gas. When the 
boiler is under low load condition, TB cannot regulate the steam temperature, and the FGR system will be kick started to extend the regulation range of steam temperature of reheater.

The boiler shown in Figure 5 adopts FGR as the main method to control the steam temperature of reheaters. This is due to the reason that first-stage reheater and second-stage reheater are convective heating surfaces, while the steam temperature of the two stage reheaters is sensitive to flue gas flow ratio. Furthermore, the ratio of FGR is adjusted under different loads to enhance convective heat absorption and to ensure that the required rated steam temperature of final first-stage reheaters and final second-stage reheaters is obtained. However, the FGR fan is needed in the system, which makes the system more complex and the house-service consumption rate as well as the initial investment increase.

\subsubsection{T-Typed Boiler}

The T-type double-reheat boiler adopted TB as the main control method for steam temperature of reheater. The layout of the heating surface is shown in Figure 7. As can be seen, the middle first-stage reheater and middle second-stage reheater are cross arranged as the semi-radiative heating surface just downstream the furnace exit. Because of this, both steam temperatures of the two stage reheaters are sensitive to burner tilting and can balance themselves. Under $60 \%$ load, the adjustment of steam temperature can be achieved by putting the upper level burner into operation to change the height of the flame's center, thus adjusting the fraction of heat absorption of radiation and convection. The SA is an auxiliary method and generally does not kick in.

Above all, in order to guarantee the temperature control capability of reheater steam in double-reheat boiler, the combination of one or two major tempering methods with an auxiliary tempering method is adopted by all types of double-reheat boilers (see Table 1), which agree with the results of Tao [39]. Tao et al. found that FGR has limited influence on the reheated steam temperature, and the higher the temperature, the weaker the effect, but the combined method which combines the combustion optimization adjustment, combustion nozzle swing, and coal mill unit moving upwards with gas recirculation adjustment was proposed.

Table 1. The detailed methods of temperature regulation of different types of double-reheat boilers in China.

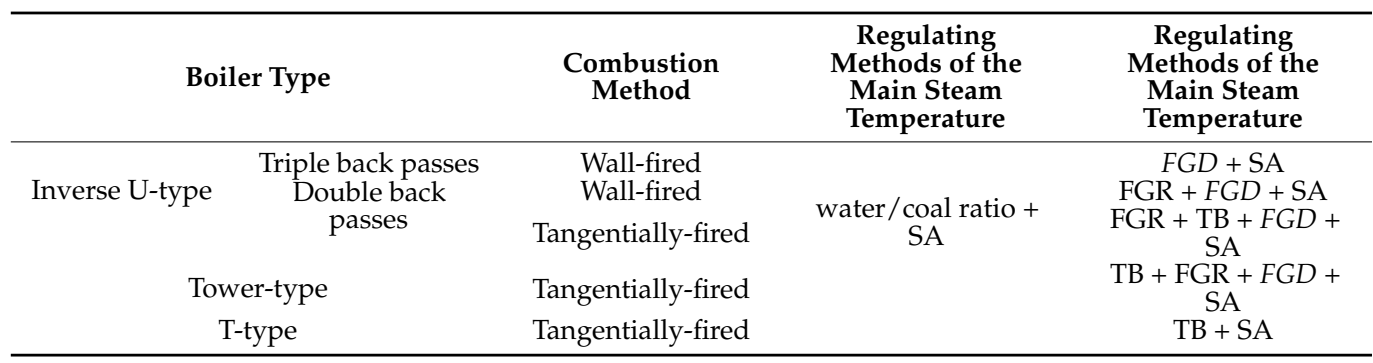

\section{Conclusions}

- The double-reheat technology in China had significant breakthroughs in terms of parameters, capacity, and system optimization. China has achieved many basic design schemes and experience for the operation and maintenance of double-reheat boiler as well as of the advanced $35 \mathrm{MPa} / 700{ }^{\circ} \mathrm{C}$ pulverized coal fired power plants.

- The core work of designing USC double-reheat boiler is to arrange the heating surface, since the double-reheat boiler has more complicated water-vapor circuitry. It is difficult to reasonably arrange the radiative and convective heating surfaces to meet the requirements of heat absorption. In addition, the parameters of working fluid nearly reach the limitation of metal material, which brings challenges for safe operation of water-cooled wall.

- The combined heating surface of the tangentially-fired tower-type double-reheat boiler has the advantage of regulating the steam temperature with TB combined with FGR. 
This is because the low-temperature part of the final second-stage reheater is arranged as the radiative or semi-radiative heating surface and the high-temperature part of final second-stage reheater is arranged as the convective heating surface.

- The steam pressure and temperature of the double-reheat boiler are approaching the limitation of tube material. It is very important to control the temperature deviation for safe and stable operation of the boiler, especially to decrease the temperature deviation of combustion and fluid sides, since a small overheating could cause the failure of the tube.

- It is an important development direction to improve the flexibility of the double-reheat boiler. This is because the double-reheat boiler has the characteristic of inherent lack of flexibility, since the water-vapor circle is complicated, while the thick wall components and the regenerative heater series are bigger compared to those of single-reheat boiler. However, the grid loads are fluctuating as more and more renewable energy power stations have connected to the grid in recent years; the double-reheat units should participate in the peaking operation.

Author Contributions: Investigation, P.Y. and J.X.; writing—original draft preparation, review and editing, H.L.; funding acquisition, L.D. and D.C. All authors have read and agreed to the published version of the manuscript.

Funding: This research was funded by the National Key R\&D Program of China, grant number 2017YFB0602102" and "The China Postdoctoral Science Foundation, grant number 2018M633507".

Conflicts of Interest: The authors declare no conflict of interest.

$\begin{array}{ll}\text { Nomenclature } \\ \text { USC } & \text { ultra-supercritical } \\ \text { SOFA } & \text { separate over fire air } \\ \text { TB } & \text { tilting burners } \\ \text { SA } & \text { spray attemperation } \\ \text { SCR } & \text { selective catalytic reduction } \\ \text { EP } & \text { electrostatic precipitator } \\ \text { FGR } & \text { flue gas recirculation } \\ \text { BMCR } & \text { boiler maximum continuous rating } \\ \text { FGD } & \text { flue gas damper } \\ \text { SH } & \text { superheater } \\ \text { AH } & \text { air heater } \\ \text { ID fan } & \text { induced draft fan }\end{array}$

\section{References}

1. Chang, S.; Jian, Z. Clean Coal Technologies in China: Current Status and Future Perspectives. Engineering 2016, 2, 447-459. [CrossRef]

2. Perrone, D.; Castiglione, T. Numerical simulations on Oxy-MILD combustion of pulverized coal in an industrial boiler. Fuel Process. Technol. 2018, 181, 361-374. [CrossRef]

3. Liu, Y.; Bisson, T. Recent developments in novel sorbents for flue gas clean up. Fuel Process. Technol. 2010, 91, 1175-1197. [CrossRef]

4. Tumanovskii, A.; Somova, E. Review of the coal-fired, over-supercritical and ultra-supercritical steam power plants. Therm. Eng. 2017, 64, 83-96. [CrossRef]

5. Feng, W. China's national demonstration project achieves around $50 \%$ net efficiency with $600{ }^{\circ} \mathrm{C}$ class materials. Fuel 2018, 223, 344-353. [CrossRef]

6. Beér, B. High efficiency electric power generation: The environmental role. Prog. Energy Combust. Sci. 2007, 33, 107-134. [CrossRef]

7. Oliver, T. Clean fossil-fuelled power generation. Energy Policy 2008, 36, 4310-4316. [CrossRef]

8. Bugge, J.; Blum, R. High-efficiency coal-fired power plants development and perspectives. Energy 2006, 31, 1437-1445. [CrossRef]

9. Dong, J.; Zhou, T. Coupled Heat Transfer Simulation of the Spiral Water Wall in a Double Reheat Ultra-supercritical Boiler. J. Therm. Sci. 2018, 27, 592-601. [CrossRef] 
10. Mehdi, R.; Aghagoli, A. Thermodynamic Analysis of a Steam Power Plant with Double Reheat and Feed Water Heaters. Adv. Mech. Eng. 2014, 6, 940818.

11. Yang, Y. Application status and development of USC unit with double-reheat cycles. Power Syst. Eng. 2013, 29, 37-38. (In Chinese)

12. Tian, D.; Zhong, L. Influence of vertical burner tilt angle on the gas temperature deviation in a 700MW low NOx tangentially fired pulverised-coal boiler. Fuel Process. Technol. 2015, 138, 616-628. [CrossRef]

13. Xu, L.; Huang, Y. Experimental research of mitigation strategy for high-temperature corrosion of waterwall fireside in a $630 \mathrm{MWe}$ tangentially fired utility boiler based on combustion adjustments. Fuel Process. Technol. 2019, 188, 1-15. [CrossRef]

14. Liu, H.; Zhang, L. Effect of FGR position on the characteristics of combustion, emission and flue gas temperature deviation in a 1000 MW tower-type double-reheat boiler with deep-air-staging. Fuel 2019, 246, 285-294. [CrossRef]

15. Wang, Y.; Mou, C. Flexibility and efficiency co-enhancement of thermal power plant by control strategy improvement considering time varying and detailed boiler heat storage characteristics. Energy 2021, 232, 121048. [CrossRef]

16. Pang, L.; Zhang, S. Flexibility Improvement Study on the Double Reheat Power Generation Unit with a High Temperature Molten Salt Thermal Energy Storage. Proc. Chin. Soc. Electr. Eng. 2021, 41, 2682-2690. (In Chinese)

17. Wang, Z.; Liu, M. Flexibility and efficiency enhancement for double-reheat coal-fired power plants by control optimization considering boiler heat storage. Energy 2020, 201, 117594. [CrossRef]

18. Zhao, Z.; Su, S. Exergy analysis of the turbine system in a $1000 \mathrm{MW}$ double reheat ultra-supercritical power plant. Energy 2017, 119, 540-548. [CrossRef]

19. Wang, Y.; Mu, C. Review of the development and application of double-reheat power generation technology. Therm. Power Gener. 2017, 46, 1-11. (In Chinese)

20. Jiang, M.; Huang, B. Prospects on Coal-fired Power Generation Technology Development. Proc. CSEE 2012, $32,1-8$.

21. National Development and Reform Commission. The Electric Power Development Planning "In 10th Five-Year" (2001-2005); National Development and Reform Commission: Beijing, China, 2001. (In Chinese)

22. National Development and Reform Commission. The Electric Power Development Planning "In 12th Five-Year" (2011-2015); National Development and Reform Commission: Beijing, China, 2011. (In Chinese)

23. National Development and Reform Commission. Action Plan for Retrofitting and Upgrading of Energy Conservation and Emission Reduction for Thermal Power Plants(2014-2020); National Development and Reform Commission: Beijing, China, 2013. (In Chinese)

24. Industry Information. The New World Record of Thermal Power Efficiency Equiped with 1 GW Double-Reheat Boiler Produced; Harbin Boiler Co., Ltd.: Harbin, China, 2016; Volume 5, p. 38. (In Chinese)

25. He, W. Match Characteristics and Influence Factors of Dongfang Double-Reheat Boiler Reheating; Chongqing University: Chongqing, China, 2015. (In Chinese)

26. Zhang, Y.; Mao, Y. The design \& operation of the first domestic 600MW double-reheat ultra-supercritical boiler. Boil. Manuf. 2016, 1, 1-6. (In Chinese)

27. Yao, D.; Zhu, Y. Design characteristics of 1000 MW double-reheat ultra-supercritical towe boiler. Boil. Technol. 2017, 48, 1-6. (In Chinese)

28. Jiang, D.; Huang, J. Engineering practice of a 1000 MW double-reheat ultra-supercritical boiler. Power Equip. 2016, 30, 421-424. (In Chinese)

29. Wang, X.; Mei, Z. Experimental study on optimization and adjustment of wall temperature of reheater tubes in an ultrasupercritical double-reheat boiler. Therm. Power Gener. 2017, 46, 101-106. (In Chinese)

30. Wang, L.; Liu, H. Analysis of superheater over-temperature of 1000MW double-reheat tower-type boiler \& its countermeasure. Shaanxi Electr. Power 2016, 44, 80-87. (In Chinese)

31. Zhao, Z.; Gao, K. Debugging and Optimization of Analog Control System for Ultra-Supercritical Units; Electric Power Press: Beijing, China, 2016; pp. 122-128. (In Chinese)

32. Zhao, Z.; Hao, D. Control and optimization of water/coal ratio for an ultra-supercritical $1000 \mathrm{MW}$ unit. Therm. Power Gener. 2017, 46, 136-140. (In Chinese)

33. Zhao, Z.; Hao, D. Double-reheat ultra-supercritical unit reheat steam temperature control. Therm. Power Gener. 2015, 44, 113-118. (In Chinese)

34. $\mathrm{Xu}, \mathrm{L}$. Discussion on the Reheat Steam Temperature Regulation Scheme in Double-reheat Unit. Electr. Power Surv. Des. 2016, 4, 39-44. (In Chinese)

35. Xu, W.; Zhang, J. Study on the Steam Temperature Characteristic of a 660 MW Flexible Double-Reheat Boiler based on Response Surface Analysis. J. Eng. Therm. Energy Power 2020, 35, 110-116. (In Chinese)

36. Che, D.F. Boilers-Theory, Design and Operation; Xi'an Jiaotong University Press: Xi'an, China, 2008.

37. Yao, X.; Jiang, D. The Double-reheat Unit Thermal Economy Research in Different Boiler Reheater Temperature Control Methods. Electr. Power Surv. Des. 2016, 3, 8-15. (In Chinese)

38. Li, C. Engineering application of reheat steam temperature control mode for double-reheat tower boilers. Therm. Power Gener. 2016, 45, 68-74. (In Chinese)

39. Tao, Q.; Wang, Y. Research on the Characteristicsof Reheat Steam Temperature Controlled by Gas Recirculation in Double-Reheat Boiler. J. Eng. Therm. Energy Power 2020, 35, 51-57. 